\title{
Buriat Language
}

National Cancer Institute

\section{Source}

National Cancer Institute. Buriat Language. NCI Thesaurus. Code C153867.

A variety of Mongolic spoken by the Buryats people of Russia and Mongolia. 